strengthen the EPF and EMSP's wider initiatives on tackling the multiple forms of discrimination faced by patients with chronic conditions.

The workshop demonstrated how many issues surrounding young people with chronic conditions transitioning into the labour market are still prevalent. The expectation of discrimination and stigma in the workplace, along with the unwillingness to disclose their condition when applying for a job for fear of rejection are confounded by young patients' experiences of negative employer attitudes. Moreover, the concept of quota systems and giving people with chronic conditions and/or disabilities preference among applicants for certain jobs possibly suggests that they are employed because they have a chronic condition and/or disability, not because of their abilities. This unambiguous form of positive discrimination also affects how young people manage information about their health. They feel forced to share about their condition to get an interview, however by doing so they risk being subjected to negative reactions in the interview or at the workplace. Young people with chronic conditions have a great deal to contribute to the workplace and more action should be taken to encourage and support employers with hiring them. Training and resources should be provided to managers and employees to raise awareness of the impact that chronic conditions can have on an individual, and how they can be assisted through small adjustments or specific care requirements. Employees should not assume what someone can or cannot do and how their condition affects them, therefore a place for an open discussion should be created. In addition, where quota systems apply, they should be re-evaluated and designed to recruit young patients on merit, in competition with other workers without a chronic condition and/or disability.

Disclosure of Interest: None declared

DOI: 10.1136/annrheumdis-2017-eular.7262

\section{SP0072 CHALLENGES AND POTENTIAL SOLUTIONS ABOUT STAYING IN WORK AS A YOUNG PERSON WITH AN RMD}

J. Andersen $1,2,3 .{ }^{1}$ Lupus Europe, Romford, Essex, United Kingdom; ${ }^{2}$ EULAR Young PARE, Zürich, Switzerland; ${ }^{3}$ Lupus Dk, Gigtforeningen, Copenhagen, Denmark

Introduction: A lot of young people with RMDs experience difficulties when it comes to staying in work after diagnosis. Some employers see a young person with an RMD-diagnosis as a liability. They are afraid it will cause a lot of difficulties with sick leaves and less work effort and in the end cost them a lot of money. Often the young person hasn't worked in the company for that many years (because of the age) and hasn't had the chance to make themselves indispensable/a valued work force yet, which makes it easy/obvious for the employer to terminate their employment.

The process of getting a diagnosis can often cause long periods of sick leave in the beginning and many employers don't understand that this will get better over time as the person gets used to having the disease and the medication has a chance to work properly.

Some young people choose not to tell their employer, that they have an illness at all, which can also be a big problem. When the employer and the work colleges don't know about the diagnosis, they cannot take special consideration to the person with the illness. Sometimes, you might a little extra break to be able to work an entire day and without it you risk wearing yourself down and having to quit the job yourself. If you choose to take the breaks yourself or perhaps fail at your job, because you try to do as much as the healthy persons, you risk getting fired, because nobody knows there is a good reason why you cannot do as much as you "should". Young and inexperienced persons can have difficulties demanding special treatment. They are often too insecure to stand their own ground and demand special consideration.

Objectives: I aim to examine the problems young people with RMDs face, when they want to stay in work and find potential solutions to these problems. How big is the problem? What can be done by the young people themselves? How can national patient organisations help them? How can EULAR PARE or other united European patient organisations help? Do we need new regulations? How do we make each country follow the EU-legislation?

Methods: I have asked young people with RMDs from all across Europe about their experiences with staying in work through social media and email. I have also asked patient organisations from all of Europe through email and personal meetings about their experiences, when it comes to young people with RMDs and work

Results: The challenges differ from country to country. In some countries having an RMD is seen as a taboo, a sign of weakness. In other countries, an RMDdiagnosis makes you no different than the rest of society and the expectations to what you can do are often too high. I will attempt to make a presentation of potential solutions to the different issues. How it could help, if patient organisations spread awareness about RMDs among employers all across Europe. How, if the young person told their employer, that they have an RMD, it might help them in the long run. There are several places where young people with RMDs can get help and advise on how to act, when they want to stay in work. There already exists EU-legislation on the area, but not all EU-states respect them and adhere to them - this has to be changed.

Disclosure of Interest: None declared

DOI: 10.1136/annrheumdis-2017-eular.7167

\section{SP0073 PRACTICAL EMPLOYABILITY SUPPORT FOR YOUNG PEOPLE WITH RMDS}

M. Mcallister. Working Well with Arthritis Joint Working Service, Arthritis Care, Glasgow, United Kingdom

Background: Arthritis Care is a UK national charity providing a range of support through three services;

Working Well with Arthritis - Joint Working employability service (Scotland only). $87 \%$ of Arthritis and Work Scotland 2016 survey respondents' state arthritis has a high or very high impact on work. Joint Working (JW) service aims to address this by:

Providing holistic employability support to individuals of working age to improve their capacity to manage their condition in work.

Providing employers support to increase understanding of arthritis within the workplace

Offering employers free Arthritis Awareness training

Young People and Families Service (YPFS) for age 10 - 25 years.

Series of free, one day or weekend workshops, to help reduce social isolation, increase confidence and management of condition.

Living Well with Arthritis offers adults access to self management support such as:

Managing pain/symptoms; activity/exercise; health walks, Tai chi for arthritis; peer support.

Objectives: Joint Working (JW) service aims to help individuals of working age with arthritis make informed decisions about work, support them to remain in, return to, or explore suitable work, training or alternative employability opportunities.

1 in every 1,000 young people in the UK has arthritis, YPFS complements medical treatment by providing additional social and emotional support, to help reduce isolation and increase resilience. With all services being delivered by Arthritis Care there is a natural crossover and support network for young people around transitioning from education to work.

The services aim to provide individuals with the knowledge, confidence, skills and support to empower them to make informed life and work decisions and access key support services - with the aim of improving their chances of remaining in work.

Method: There is a partnership and referral process to JW via NHS Rheumatology Occupational Therapy staff, within specific NHS areas, though referral to JW is open to anyone with arthritis.

Partnership working with; NHS, employability networks and Arthritis Care YPFS is key to the success of JW service.

Individuals with arthritis often find; communicating their needs, understanding their rights and navigating the system can be complex and overwhelming. Joint Working provides support through a range of mediums; 1 to 1 meetings (where practical), email and/or phone. Exploring areas of concern, improving understanding of rights, awareness of, and access to national employment support schemes, mainstream or disability employability services.

Results: Young people who have used Joint Working service have been supported to access a range of services; obtaining specialist equipment or travel support to remain in work, returning to work after many years unemployed, work placement to support university course, volunteering or specialist employability opportunities, Conclusions: The employability interventions have positive psychosocial benefits, reducing feelings of isolation, increasing confidence and raising aspirations.

People with arthritis value the opportunity to discuss any issues they have remaining in, returning to or embarking on a career path.

The ongoing access to all Arthritis Cares services, ensure young people have a long-term support network.

Maureenm@arthritiscare.org.uk

Disclosure of Interest: None declared

DOI: 10.1136/annrheumdis-2017-eular.7149

\section{THURSDAY, 15 JUNE 2017 \\ Epidemiology of rheumatic and musculoskeletal diseases - a critical appraisal}

\section{SP0074 THE FUTURE OF EPIDEMIOLOGICAL RESEARCH IN RHEUMATIC AND MUSCULOSKELETAL DISORDERS}

L. Gossec. Rheumatology Department, Paris 06 University, Pitié-Salpétrière Hospital, Paris, France

Epidemiological research has gone through a very exciting time over the past years in rheumatic and musculoskeletal disorders (RMDs). The future is just as exciting. Although 'traditional' epidemiology in terms of prevalence and incidence of diseases is quite well-known now, there are many gaps to our knowledge in particular in the field of outcomes research (what to assess, when and how?) but also in the field of predictive factors (e.g. predictive factors of severity and of treatment response). Better knowledge in outcomes assessment is key to feasibility of standardised assessments and is the basis of shared decision making. Better knowledge of predictive factors will open the door to truly personalised medicine. Some future directions will be discussed in this talk. 